\title{
Tracking and orbit determination performance of the GRAS instrument on MetOp-A
}

\author{
Oliver Montenbruck · Yago Andres · Heike Bock - Tom van Helleputte · \\ Jose van den Ijssel · Marc Loiselet · Christian Marquardt · Pierluigi Silvestrin • \\ Pieter Visser · Yoke Yoon
}

Received: 27 October 2007/ Accepted: 25 February 2008/Published online: 9 April 2008

(C) Springer-Verlag 2008

\begin{abstract}
The global navigation satellite system receiver for atmospheric sounding (GRAS) on MetOp-A is the first European GPS receiver providing dual-frequency navigation and occultation measurements from a spaceborne platform on a routine basis. The receiver is based on ESA's AGGA-2 correlator chip, which implements a high-quality tracking scheme for semi-codeless $\mathrm{P}(\mathrm{Y})$ code tracking on the L1 and L2 frequency. Data collected with the zenith antenna on MetOp-A have been used to perform an inflight characterization of the GRAS instrument with focus on the tracking and navigation performance. Besides an assessment of the receiver noise and systematic measurement errors, the study addresses the precise orbit determination accuracy achievable with the GRAS receiver. A consistency on the $5 \mathrm{~cm}$ level is demonstrated for
\end{abstract}

O. Montenbruck $(\bowtie) \cdot$ Y. Yoon

German Space Operations Center,

Deutsches Zentrum für Luft- und Raumfahrt,

82230 Weßling, Germany

e-mail: oliver.montenbruck@dlr.de

Y. Andres · C. Marquardt

Eumetsat, Am Kavalleriesand 31, 64295 Darmstadt, Germany

H. Bock

Astronomisches Institut der Universität Bern,

Sidlerstrasse 5, 3012 Bern, Switzerland

T. van Helleputte $\cdot$ J. van den Ijssel $\cdot$ P. Visser

Delft Institute of Earth Observation and Space Systems,

Delft University of Technology, Kluyverweg 1,

2629 HS Delft, The Netherlands

M. Loiselet · P. Silvestrin

ESA/ESTEC, Keplerlaan 1,

2200 AG Noordwijk ZH,

The Netherlands reduced dynamics orbit solutions computed independently by four different agencies and software packages. With purely kinematic solutions, $10 \mathrm{~cm}$ accuracy is obtained. As a part of the analysis, an empirical antenna offset correction and preliminary phase center correction map are derived, which notably reduce the carrier phase residuals and improve the consistency of kinematic orbit determination results.

Keywords Precise orbit determination - Phase center variation · Tracking loops - Semi-codeless tracking .

AGGA-2 - GRAS · MetOp

\section{Introduction}

MetOp is a joint project of the European space agency (ESA) and the European organisation for the exploitation of meteorological satellites (Eumetsat), which provides spaceborne measurements for weather prediction and climatology. MetOp-A, the first satellite, was injected into Sun-synchronous polar orbit at $800-\mathrm{km}$ altitude on 19 October 2006. Follow-on launches are planned once every 5 years to achieve a continued 14 years service (Edwards et al. 2006).

Among the key instruments of the MetOp satellites is the global navigation satellite system receiver for atmospheric sounding (GRAS; Loiselet et al. 2000). The GRAS receiver provides GPS occultation measurements and navigation data based on which bending angles and meteorological data are derived. So far, the instrument has performed flawlessly and provided an average of more than 650 rising and setting occultation measurements per day (Loiselet et al. 2007).

The use of GRAS on MetOp-A represents the first long duration flight of a GPS receiver based on the AGGA2 
Advanced GPS/GLONASS ASIC correlator chip (Silvestrin et al. 2000). This correlator employs an innovative semi-codeless tracking concept (Silvestrin and Cooper 2000) which resembles the well-known Z-tracking scheme (see e.g. Woo 2000) for encrypted P-code, but is expected to provide a better estimation of the $\mathrm{W}$-code bit and thus a reduction of the implied squaring-losses. The same chipset will be used in the Lagrange receiver (Zin et al. 2006) to be flown on GOCE as well as in the new receivers under consideration for Swarm (Reichinger et al. 2006) and Sentinel-3. GRAS measurements are therefore of high interest in order to understand better the capabilities of AGGA based receivers and to assess implications for the quality of derived scientific products.

With this background, a dedicated study has been performed by DLR (German Aerospace Center), AIUB (Astronomical Institute of the University of Bern) and DEOS (Delft Institute of Earth Observation and Space Systems) to assess the performance of the GRAS instrument independent from the operational processing segment at Eumetsat. The study has intentionally been confined to navigation related measurements collected with the zenith antenna. It focuses on the analysis of the tracking performance and the achievable orbit determination accuracy, but does not address occultation measurements and derived products. Initial occultation results are discussed in Loiselet et al. (2007) and Marquardt et al. (2007).

All results presented in this report are based on a 3-day data set for 26-28 December 2006 (day 360-362), which has been released by the mission management for this study. Instrument service packets (ISPs) with raw telemetry data from the GRAS instrument have been provided on a once-per-orbit basis and were preprocessed as discussed in the subsequent section. Despite the limited duration of the available data set, valuable conclusions on the GRAS performance and POD accuracy could be derived.

\section{Measurement assembly and correction}

Being primarily designed as a scientific instrument for radio occultation measurements rather than a standard GPS receiver, the GRAS instrument provides raw correlator level measurements that require several stages of preprocessing prior to their use for precise orbit determination. In order to obtain conventional pseudorange, carrier phase and carrier-to-noise-density measurements, information from various raw data telemetry packages must be processed, interpolated and fused (SAAB 2004). For use within this study, a dedicated preprocessing and RINEX conversion tool has been developed that facilitates the use of GRAS GPS measurements inside heritage software packages for precise orbit determination.

All GRAS raw measurements are time-tagged in terms of instrument measurement time (IMT), which counts the integer clock beats of the ultrastable $28.25-\mathrm{MHz}$ oscillator (USO) and serves as a basis for the receiver time scale. For the GRAS unit of MetOp-A, the oscillator used exhibits a frequency offset of about $+3 \mathrm{~ns} / \mathrm{s}$, which results in an almost linear growth of the receiver time clock offset. Over a $24 \mathrm{~h}$ arc, this accumulates into clock offsets of roughly $0.5 \mathrm{~ms}$ and pseudorange offsets of $150 \mathrm{~km}$ (Fig. 1). A clock-offset correction is therefore desirable prior to the use of the GRAS measurements for precise orbit determinations. Given the high stability of the GRAS USO, the clock offset may be represented by a second order polynomial in receiver time. The corrected clock offset (Fig. 1) is generally confined to less than $10 \mathrm{~m}$ (30 ns) and exhibits orbit-periodic variations with amplitude of about $\pm 3 \mathrm{~m}$ (10 ns). These may be attributed to changes in the external USO temperature of about $1 \mathrm{~K}$. When referred to the external USO temperature, a range-rate variation of $5.6 \mathrm{~mm} / \mathrm{s} / \mathrm{K}$ can be inferred from the observed clock offsets (Fig. 2), which corresponds to a frequency variation of
Fig. 1 Clock offset variation of the uncorrected MetOp-A GRAS receiver time (top) and after removal of a quadratic polynomial for the receiver time minus GPS time difference (bottom)
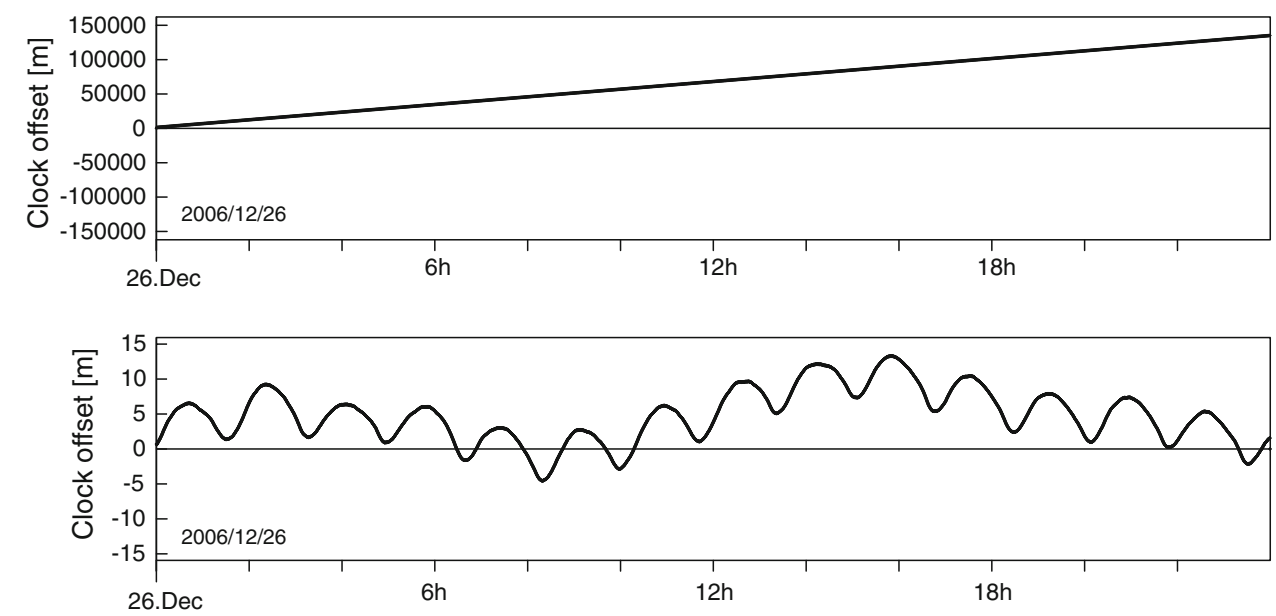


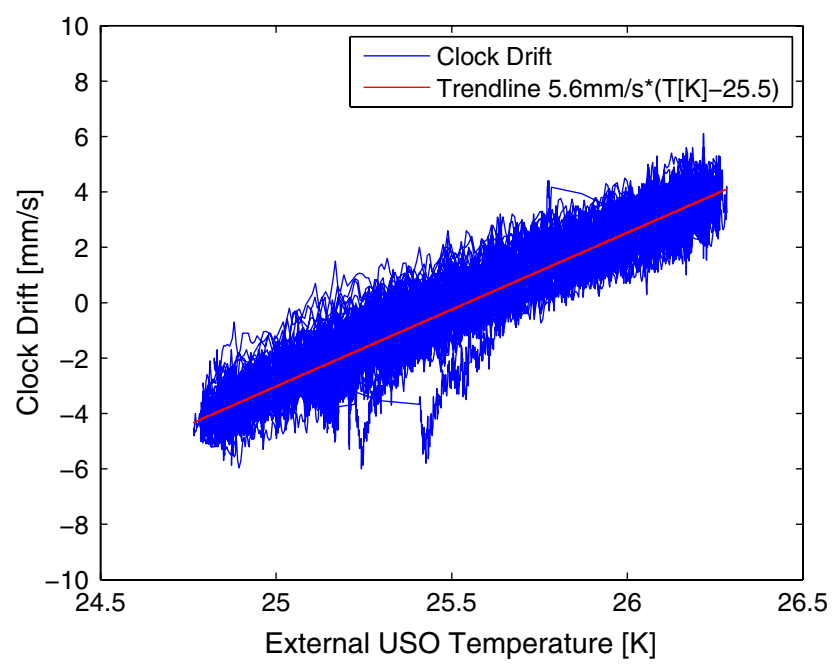

Fig. 2 Variation of GRAS oscillator frequency with external USO temperature

$\mathrm{d}(\Delta f / f) / \mathrm{d} T=2 \times 10^{-11} / \mathrm{K}$ and well surpasses the specification of $5 \times 10^{-11} / \mathrm{K}$.

For the generation of pseudoranges measurements, the P1 and P2 code phases are first assembled from the respective raw data packet. The resulting value exhibits a $0.5 \mathrm{~s}$ ambiguity, which can be resolved by demanding the pseudorange to be less than $150,000 \mathrm{~km}$. The $\mathrm{C} / \mathrm{A}$ code phase is constructed in a similar manner and yields a pseudorange with an ambiguity of $1 \mathrm{~ms}$ or $300 \mathrm{~km}$. This ambiguity can be resolved by constraining the $\mathrm{C} / \mathrm{A}$ pseudorange to an interval of $\pm 150 \mathrm{~km}$ around the P1 pseudorange. Measurements on the individual GRAS receiver channels are generated at differing epochs offset by $40 \mathrm{~ms}$ intervals. To obtain synchronized measurements, all pseudoranges are interpolated to the nearest integer second of receiver time using a third-order polynomial based on four consecutive $1 \mathrm{~Hz}$ data points. As a result of the interpolation, the noise of the computed pseudoranges is about $12 \%$ smaller on average than the noise of the raw measurements. Instrument specific group delays have been considered as constant corrections with values of $-0.05 \mathrm{~m}$ (C/A code), $+114.06 \mathrm{~m}(\mathrm{P} 1$ code $)$ and $+124.52 \mathrm{~m}(\mathrm{P} 2$ code), respectively.

Carrier phases are constructed based on the phase of the numerically controlled oscillators (NCO) and residual IQ vectors. To obtain the carrier beat phase relative to the nominal L1 or L2 frequency, the measurement must be compensated for the nominal NCO frequency of 1.8717 and $3.433 \mathrm{MHz}$, respectively. Since carrier phase measurements in the GRAS instrument are latched at the end of a C/A code accumulation interval, they are neither synchronized among the individual channels nor synchronized with the corresponding code phase measurements. A third order polynomial interpolation is therefore applied to refer all data to a common integer second output epoch. As a byproduct, the derivative of the interpolating polynomial can furthermore be used to obtain Doppler (or pseudorangerate) measurements for kinematic velocity solutions.

For navigation purposes, the GRAS instrument employs a zenith looking antenna (GZA) mounted on the top surface of the MetOp satellite (Fig. 3). The antenna is made up of two independent annular patch elements for the L1 and L2 frequency, respectively, which exhibit a horizontal offset of about $134 \mathrm{~mm}$ (center-to-center). A common antenna reference point for center-of-mass corrections is defined near the geometric center of the entire antenna assembly. The GZA antenna is rotated by a $45^{\circ}$ yaw angle relative to the spacecraft body axes. As a result, the L1 element is offset by about $67 \mathrm{~mm}$ in the $-X /-Y$-direction (forward-right) relative to the antenna reference point, while the $\mathrm{L} 2$ element is offset by the same amount in the $+X /+Y$ (backwards-left) direction. Approximate antenna coordinates in the spacecraft reference frame and relative to the center-of-mass are summarized in Table 1. Phase center variations for the individual antenna elements range from about -10 to $+10 \mathrm{~mm}$ and have been calibrated prior to the flight in an
Fig. 3 The GRAS GZA antenna (left) and its location on the MetOp spacecraft (right) (courtesy SAAB/ESA)
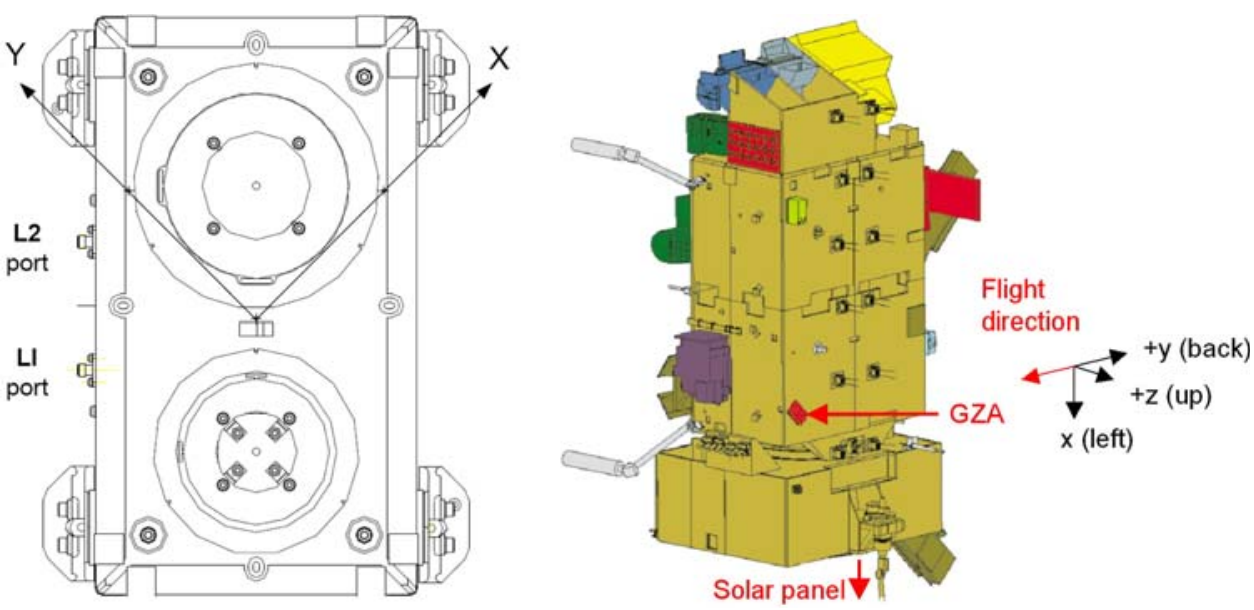
Table 1 Approximate GZA antenna coordinates (begin-of-life values relative to center of mass for MetOp-A)

\begin{tabular}{lccc}
\hline Point & $X(\mathrm{~m})$ & $Y(\mathrm{~m})$ & $Z(\mathrm{~m})$ \\
\hline Antenna reference point & -0.098 & -1.141 & +0.916 \\
L1 antenna element center & -0.145 & -1.188 & +0.916 \\
L2 antenna element center & -0.051 & -1.094 & +0.916 \\
\hline
\end{tabular}
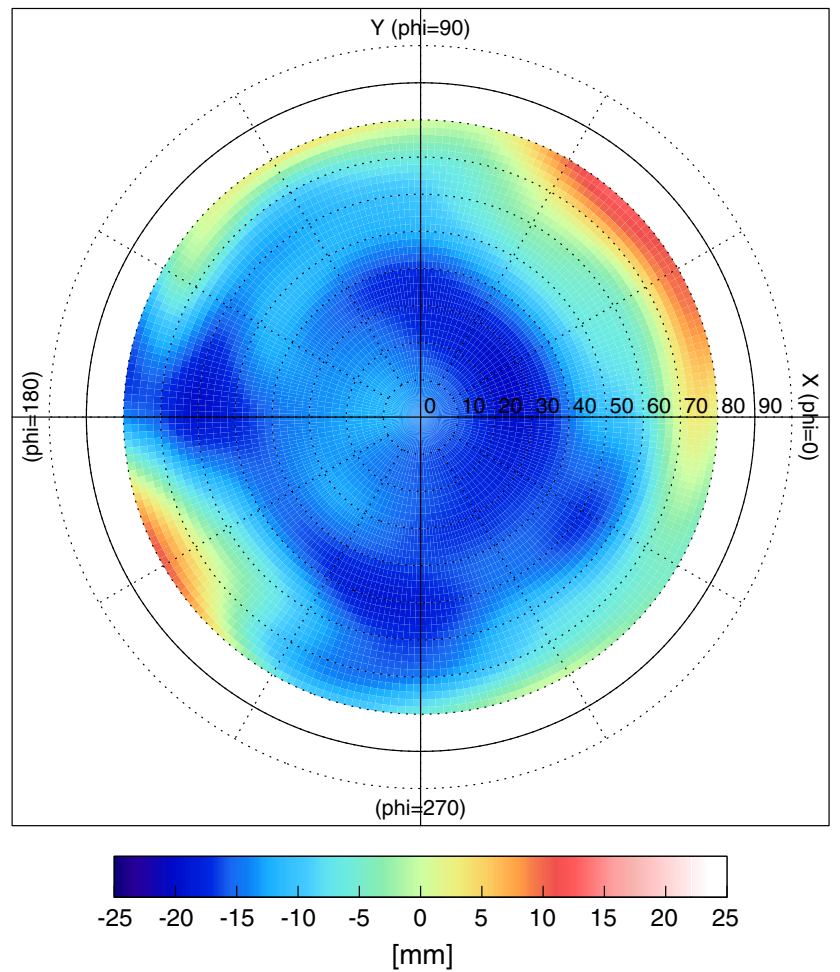

Fig. 4 Combined effect of phase center variations of the GRAS L1 and L2 antennas for the ionosphere-free L1/L2 carrier phase combination. The employed antenna coordinate system is aligned with the spacecraft body axes

anechoic chamber. Their combined effect on the ionosphere-free L1/L2 combination is illustrated in Fig. 4.

\section{Receiver performance analysis}

The GRAS instrument has been found to provide proper dual-frequency tracking of GPS satellites above the hard coded $10^{\circ}$ elevation limit. In accord with the available number of channels for the zenith-pointing antenna, a maximum of eight satellites can be tracked but six or more satellites are tracked for $98.7 \%$ of the time (Fig. 5). Only in $0.3 \%$ of all epochs, the number of tracked channels dropped to the minimum of four satellites that are required for a kinematic navigation solution.

The carrier-to-noise density ratio $\left(C / N_{0}\right)$ exhibits peak values of $57 \mathrm{~dB}-\mathrm{Hz}$ for $\mathrm{L} 1 \mathrm{C} / \mathrm{A}$ code tracking with a mean value of $40 \mathrm{~dB}-\mathrm{Hz}$ at the $10^{\circ}$ elevation limit (Fig. 6). Despite the use of widely different hardware designs, the measured variation of $C / N_{0}$ with elevation closely matches that of the receiver/antenna combinations used on CHAMP, GRACE and TerraSAR-X (see, for example, Montenbruck and Kroes 2003). For semi-codeless P-code tracking on $\mathrm{L} 1$ and $\mathrm{L} 2$, the $C / N_{0}$ values vary between $50 \mathrm{~dB}-\mathrm{Hz}$ at high elevations and a mean value of $19 \mathrm{~dB}-\mathrm{Hz}$ at the low elevation limit.

In accord with the expectations, the squaring losses (in $\mathrm{dB}-\mathrm{Hz}$ ) of the semi-codeless tracking grow linearly with decreasing signal strength. They amount to roughly $12 \mathrm{~dB}$ at a C/A code $C / N_{0}$ value of $50 \mathrm{~dB}-\mathrm{Hz}$ but increase to $22 \mathrm{~dB}$ at $40 \mathrm{~dB}-\mathrm{Hz}$ (Fig. 6). Compared to the PolaRx2 receiver, which employs a similar correlator and tracking scheme (Montenbruck et al. 2006), the semi-codeless tracking losses are roughly $2.5 \mathrm{~dB}$ higher in the GRAS instrument. It remains to be clarified whether this reflects the actual performance degradation or a systematic underestimation of the carrier-to-noise-densities.

Following the methodology outlined in Montenbruck et al. (2006), we used the geometry and ionosphere-free multipath combination to analyze the pseudorange accuracy of the GRAS instrument. Results are presented in Fig. 7 as a function of the carrier-to-noise-density ratio. Compared to the noise of a delay locked loop with a bandwidth of $0.5 \mathrm{~Hz}$ and an early-late correlator spacing of 0.14 chips (van Dierendonck 1995), the measured C/A code noise is roughly $20 \%$ higher than the predicted from the GRAS design values. Based on the measurement residuals in the precise orbit determination process (see next section), rms pseudorange errors of 0.28 and $0.35 \mathrm{~m}$ have been derived for C/A- and $\mathrm{P}(\mathrm{Y})$-code measurements, respectively. These values represent an average over all satellites tracked with the zenith antenna and include the contributions of both tracking noise and multipath.

The carrier phase accuracy has been assessed from the scatter of $3 \mathrm{~Hz}$ measurement samples relative to a fourth order Savitzky-Golay smoothing polynomial (Press et al. 1992) over a sliding $7 \mathrm{~s}$ interval. Here, noise levels of $0.2-$ 0.5 and $0.1-5 \mathrm{~mm}$ have been obtained for the L1 carrier phase measurements from the direct C/A-code tracking and for the L1/L2 carrier phase measurements from the semicodeless P-code tracking, respectively (Fig. 7). Based on the theoretical relation between carrier phase noise, signal strength and phase-locked-loop (PLL) bandwidth (Ward 1996), an effective noise bandwidth of $1 \mathrm{~Hz}$ is obtained for the LA phase measurements. It should be noted, however, that this value actually reflects the bandwidth of the filtering performed within the measurement assembly and preprocessing. The carrier phase tracking loop itself has a much higher bandwidth of $10 \mathrm{~Hz}$ to properly follow the signal dynamics in low Earth orbit. For the semi-codeless 
Fig. 5 Sky coverage and histogram of the observed GPS satellites for day $361 / 2006$
Fig. 6 Signal strength versus elevation (left) and semicodeless tracking losses (right) of the GRAS instrument on MetOp-A
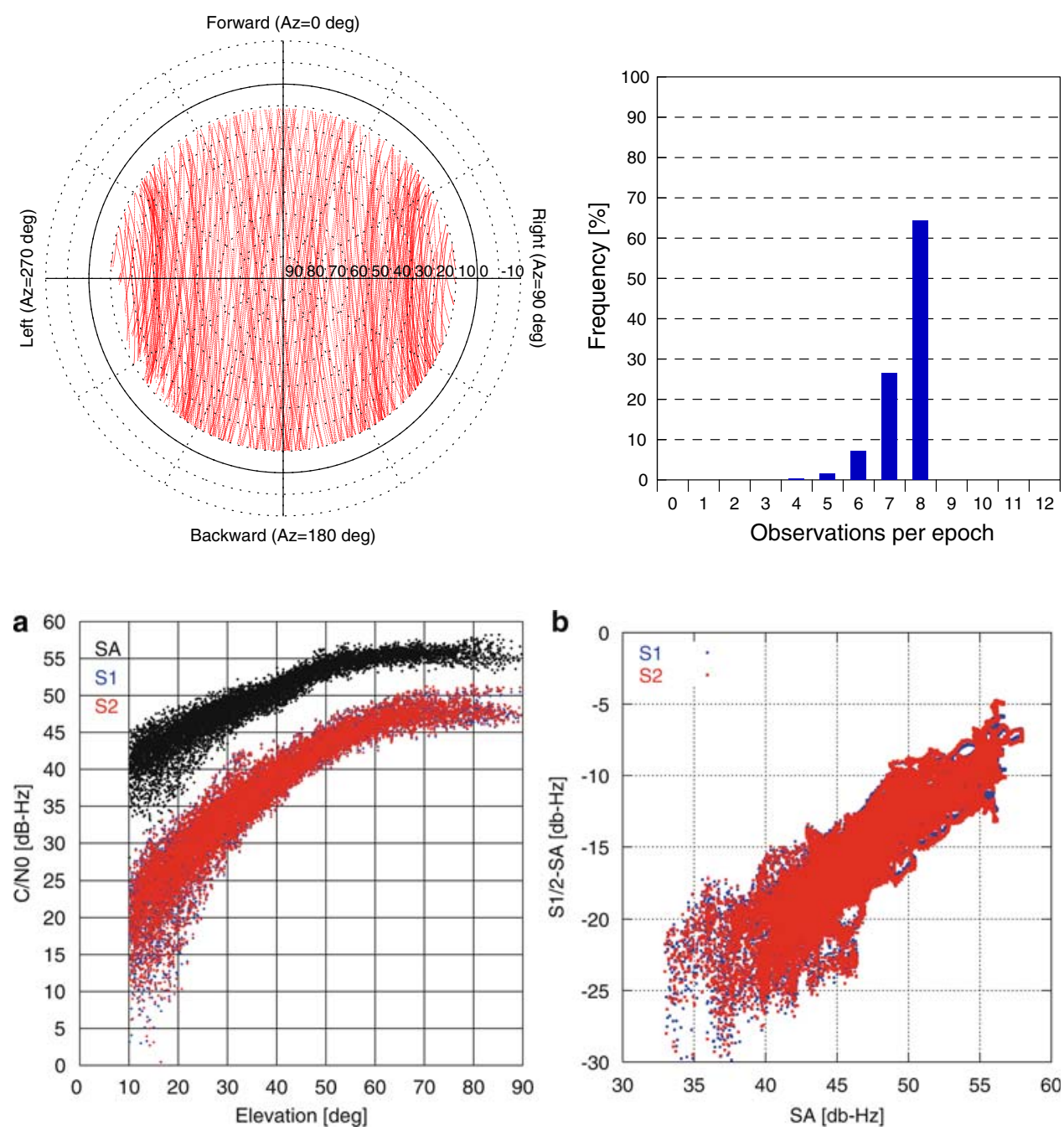

Fig. 7 Pseudorange noise (left) and carrier phase noise (right) versus $C / N_{0}$ for the GRAS instrument in comparison with the IGOR receiver

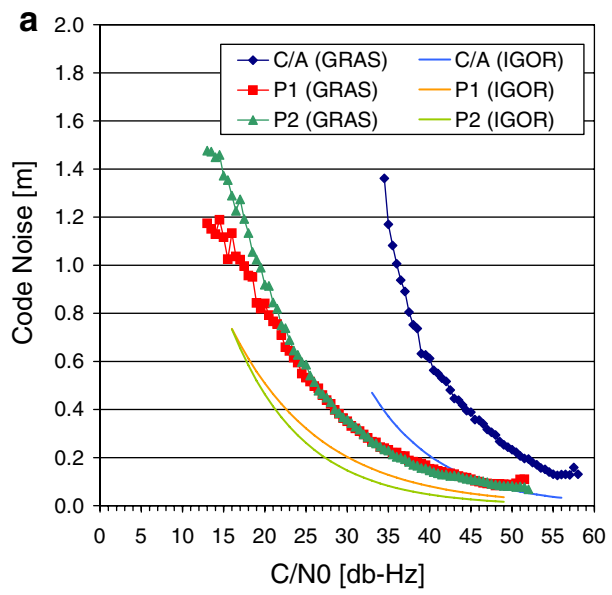

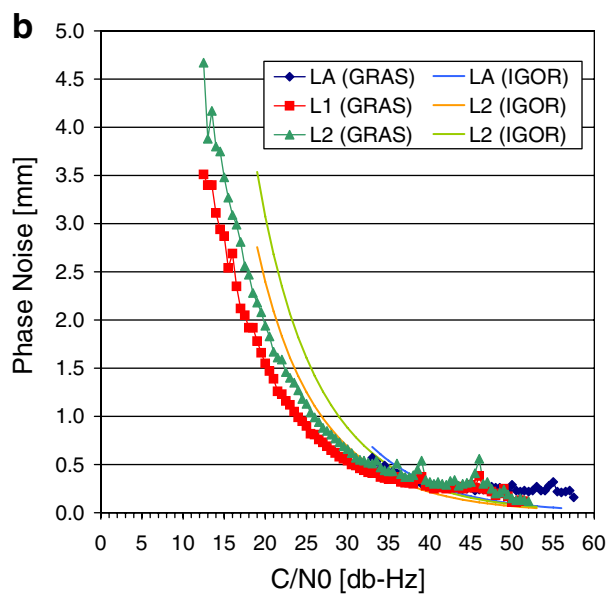

L1 and L2 carrier phase measurements, we derived effective bandwidths of $0.2 \mathrm{~Hz}$ based on the corresponding models of Woo (2000).

Concerning systematic errors, moderate amounts of multipath in the pseudorange data can be recognized over a wide range of elevations. Except for a few line-of-sight directions at low elevation, the amplitude of code multipath on the individual frequencies is mostly below $0.2 \mathrm{~m}$. Associated variations in $C / N_{0}$ are typically confined to less than $0.5 \mathrm{~dB}$. In most cases, multipath errors are due to diffuse reflections at the spacecraft body, which results in a static multipath pattern that depends only on the line- 
of-sight direction relative to the antenna. The combined effect of P1 and P2 code-multipath on the ionosphere-free pseudorange combination is illustrated in Fig. 8. In addition to the static multipath component, occasional strong reflections with $C / N_{0}$ variations up to $5 \mathrm{~dB}$ and multipath amplitudes up to $2 \mathrm{~m}$ in each frequency could be identified (Fig. 9). These do not show up in the average multipath map and are apparently dependent on the solar panel orientation. Besides code multipath, phase variations on the level of $5-10 \mathrm{~mm}$ (for the ionosphere-free L1/L2 combination) are evident from an analysis of carrier phase residuals in the precise orbit determination. These are further described in the subsequent section.

Compared to the BlackJack/IGOR receiver on CHAMP, GRACE and TerraSAR-X (Montenbruck et al. 2006), the GRAS instrument exhibits up to two times larger pseudorange measurement noise, which can be attributed to its more conservative loop settings. The GRAS instrument is free of any cross talk between different antenna front-ends that has been observed in the BlackJack/IGOR receiver (Montenbruck and Kroes 2003) and affects navigation measurements during activation of the occultation antenna. For carrier phase measurements, a similar performance is obtained for both receivers.
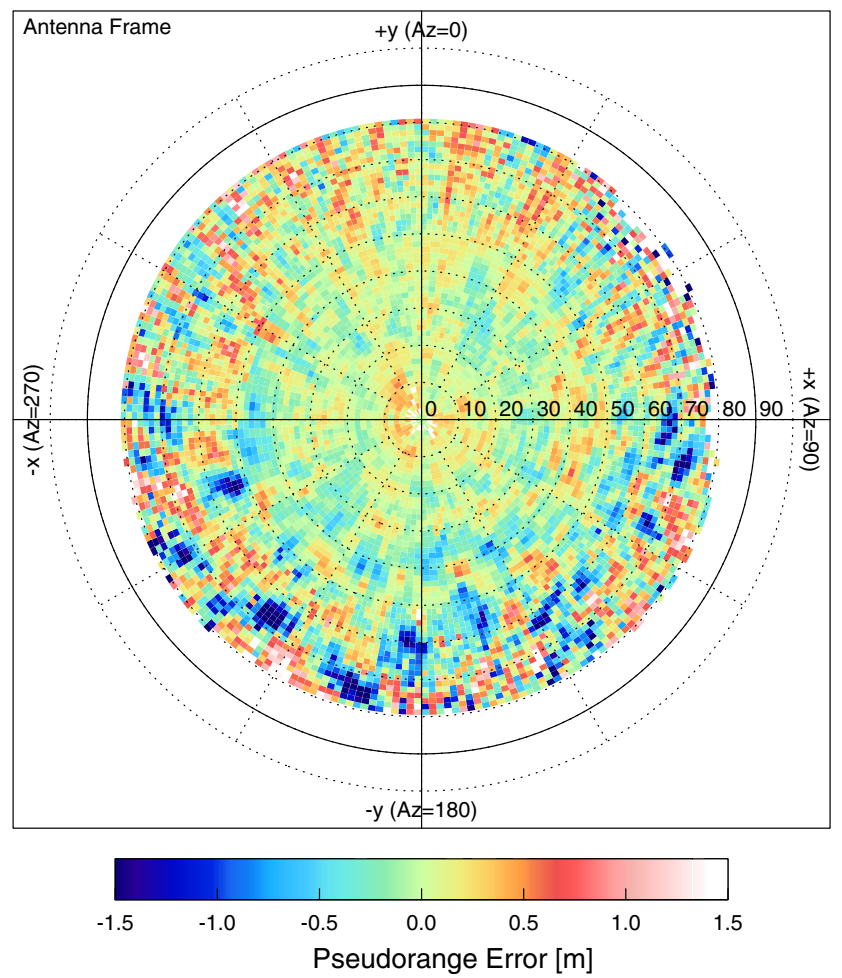

Fig. 8 Multipath-map for the ionosphere-free P1/P2 pseudorange combination
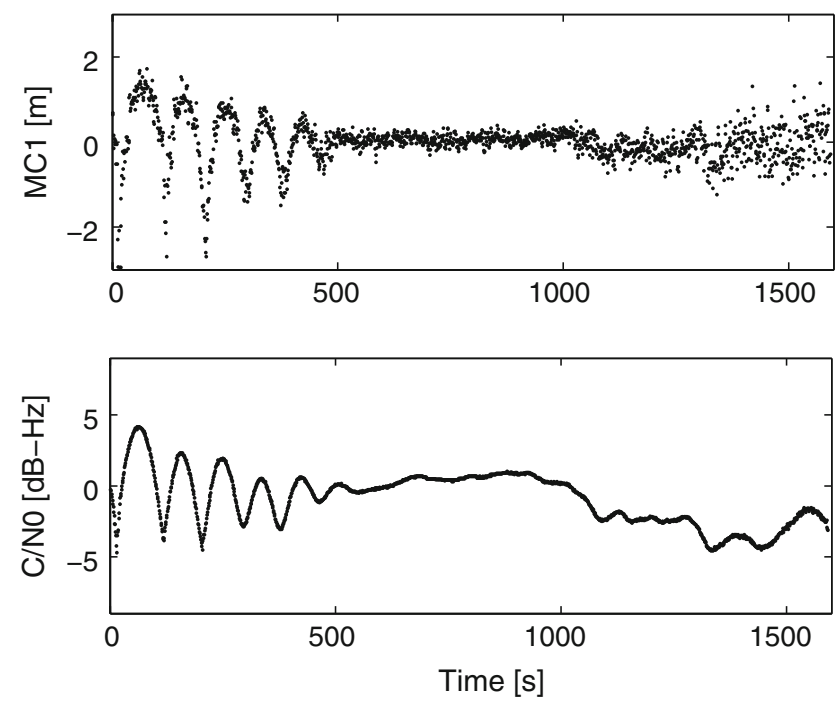

Fig. 9 Multipath (MC1) of C/A code measurements and associated $C / N_{0}$ variation in the course of a strong reflection event of PRN 6 (day $361 / 2006,2: 02$ to $2: 30 \mathrm{UTC}$ ). $C / N_{0}$ values have been detrended to remove the nominal elevation dependence

\section{Precise orbit determination}

The generation of atmospheric bending profiles from the GRAS occultation data requires knowledge of the MetOp along-track velocity to an accuracy of $0.1 \mathrm{~mm} / \mathrm{s}$, which corresponds to knowing the position of a low-orbiting satellite to about $10 \mathrm{~cm}$. Similar precise orbit determination accuracies are required for other science and Earth observation missions that plan to use AGGA-based GPS receivers. An effort has therefore been made to assess the orbit determination (POD) accuracy that can be achieved from dual-frequency code and carrier phase measurements of the GRAS receiver. Since MetOp does not carry a satellite laser reflector in order to independently validate the quality of precise orbit products, an inter-comparison of POD solutions generated independently with four different software packages has been conducted. These include

- the Bernese v5.0 GPS Software (BSW; Dach et al. 2007) used at AIUB,

- the NASA Goddard Space Flight Center GEODYN v0302 software package (Rowlands et al. 1995) used at DEOS,

- the GHOST GPS High-Precision Orbit Determination Software Tools (Montenbruck et al. 2005) used at DLR, and

- the GNSS version of ESA's Navigation Package for Earth Orbiting Satellites (NAPEOS; Agueda and Zandbergen 2004) used at Eumetsat.

An overview of the modeling and processing standards used is summarized in Table 2. Overall, the programs are considered sufficiently independent to allow a realistic 
Table 2 Summary of the dynamical and measurement models employed for the GPS based reduced dynamic orbit determination of MetOp-A

\begin{tabular}{|c|c|c|c|c|}
\hline Item & AIUB (BSW) & DEOS (GEODYN) & DLR (GHOST) & EUM (NAPEOS) \\
\hline $\begin{array}{l}\text { GPS measurement } \\
\text { model }\end{array}$ & $\begin{array}{l}\text { Undifferenced ionosphere- } \\
\text { free phase; } 30 \mathrm{~s} \text { sampling; } \\
\text { phase center offsets and } \\
\text { variations of transmitter } \\
\text { and receiver antennas; } \\
\text { phase wind-up; CODE } \\
\text { final GPS orbits and } 30 \mathrm{~s} \\
\text { clocks }\end{array}$ & $\begin{array}{l}\text { Triple-differenced } \\
\text { ionosphere-free phase, } \\
\text { 30 s sampling; corrected } \\
\text { for GRAS PCO and PCV; } \\
\text { final IGS GPS ephemeris } \\
\text { products; Hopfield } \\
\text { troposphere model; } 17 \\
\text { IGS stations (ITRF2000) } \\
\text { solid Earth and pole tides } \\
\text { station displacement }\end{array}$ & $\begin{array}{l}\text { Undifferenced ionosphere- } \\
\text { free code and phase; } 30 \mathrm{~s} \\
\text { sampling; phase center } \\
\text { offsets and variations of } \\
\text { transmitter and receiver } \\
\text { antennas; phase wind-up; } \\
\text { CODE final GPS orbits } \\
\text { and } 30 \mathrm{~s} \text { clocks }\end{array}$ & $\begin{array}{l}\text { Undifferenced ionosphere- } \\
\text { free code and phase, } 30 \mathrm{~s} \\
\text { sampling; phase center } \\
\text { offsets and variations of } \\
\text { transmitter and receiver } \\
\text { antennas; no phase wind- } \\
\text { up; CODE final GPS orbits } \\
\text { and } 30 \mathrm{~s} \text { clocks }\end{array}$ \\
\hline Gravitational forces & $\begin{array}{l}\text { GGM01 gravity }(70 \times 70) \text {, } \\
\text { solid-earth, pole and ocean } \\
\text { tides (IERS2003, } \\
\text { GOT00.2); luni-solar- } \\
\text { planetary gravity (DE- } \\
\text { 405) }\end{array}$ & $\begin{array}{l}\text { EIGEN-1S gravity model; } \\
\text { solid-earth and ocean } \\
\text { tides (EGM96); luni- } \\
\text { solar-planetary gravity } \\
\text { (DE-200) }\end{array}$ & $\begin{array}{l}\text { GGM01 gravity } \\
\text { (100 × 100); solid-earth, } \\
\text { pole and ocean tides } \\
\text { (IERS2003, TOPEX_3.0); } \\
\text { luni-solar gravity } \\
\text { (analytical ephemerides) }\end{array}$ & $\begin{array}{l}\text { EIGEN-GL04C }(120 \times 120) \\
\text { gravity model, solid-earth, } \\
\text { pole and ocean tides } \\
\text { (IERS2003, TOPEX_3.0); } \\
\text { luni-solar-planetary } \\
\text { gravity (DE-200) }\end{array}$ \\
\hline $\begin{array}{l}\text { Non-gravitational } \\
\text { forces }\end{array}$ & $\begin{array}{l}\text { No drag and radiation force } \\
\text { model; pseudo-stochastic } \\
\text { RTN accelerations at } \\
6 \text { min intervals }\end{array}$ & $\begin{array}{l}\text { MSIS-86 density model; } \\
\text { solar radiation pressure; } \\
\text { empirical RTN } \\
\text { accelerations at } 20 \mathrm{~min} \\
\text { intervals }\end{array}$ & $\begin{array}{l}\text { Jacchia-Gill density model; } \\
\text { solar radiation pressure; } \\
\text { empirical RTN } \\
\text { accelerations at } 10 \mathrm{~min} \\
\text { intervals }\end{array}$ & $\begin{array}{l}\text { MSIS- } 90 \text { density model } \\
\text { 1estimated CD/6 h; solar } \\
\text { radiation pressure; } \\
\text { empirical } 1 / \mathrm{rev} \text { cos/sin } \\
\text { acceleration in along and } \\
\text { cross track at } 12 \mathrm{~h} \\
\text { intervals }\end{array}$ \\
\hline Reference frames & $\begin{array}{l}\text { IERS2003 reference frame } \\
\text { transformations; CODE } \\
\text { final EOP solutions; } \\
\text { nominal s/c attitude }\end{array}$ & $\begin{array}{l}\text { EME2000; IAU } 1980 \\
\text { standards; final IERS } \\
\text { EOP series; nominal s/c } \\
\text { attitude }\end{array}$ & $\begin{array}{l}\text { EME2000; IAU } 1980 \\
\text { standards, IERS igs96p02 } \\
\text { EOP series; nominal s/c } \\
\text { attitude }\end{array}$ & $\begin{array}{l}\text { IERS2003 reference frame } \\
\text { transformations; IERS } \\
\text { EOP series; nominal s/c } \\
\text { attitude }\end{array}$ \\
\hline Estimation & Batch least squares & Batch least squares & Batch least squares & Batch least squares \\
\hline
\end{tabular}

assessment of the resulting accuracy assessment from the difference of individual solutions.

Supplementary to the reduced dynamic orbit determination, purely kinematic position solutions have been computed using BSW and GHOST. These solutions make no assumptions on the satellite motion and are not constrained by dynamical laws or models for the orbital motion of the host spacecraft. Kinematic POD solutions are therefore of particular interest for gravity research, for example see Svehla and Rothacher (2005), and will be a standard data product for the GOCE mission (Rummel et al. 2004; Bock et al. 2007). Due to the lack of dynamical constraints, the kinematic solutions are generally more sensitive to measurement and modeling errors than reduced dynamics orbits.

The consistency of individual orbit solutions is comparable with the results of interagency comparisons conducted for other science missions such as GRACE and Jason, and underlines the high overall quality of the GRAS measurements. As shown in Tables 3 and 4, the MetOp-A reduced dynamic orbit determination solutions computed by the individual centers agree to a level of $5 \mathrm{~cm}$ and $0.06 \mathrm{~mm} / \mathrm{s}$ for the $3 \mathrm{D} \mathrm{rms}$ position and velocity differences, respectively. Kinematic positions match the reduced dynamic results within about $10 \mathrm{~cm}$ (Table 5). For completeness, we note that overlap computations based on $30 \mathrm{~h}$ data arcs yield a 3D rms consistency of about $2 \mathrm{~cm}$, which underestimates the actual errors by a factor of 2-3.

A systematic difference of about $3 \mathrm{~cm}$ in the radial position is observed in comparison of the AIUB reduced dynamic orbit solutions with the other results. Likewise, all kinematic positioning results show a $2-4 \mathrm{~cm}$ radial offsets with respect to the reduced dynamic solutions. These radial offsets are most likely related to a systematic bias of the assumed vector between the spacecraft center-of-mass and antenna phase center locations and suggest that the distance in the $+Z$ direction should be reduced accordingly (Table 1). Such a bias would fully map into kinematic and weakly dynamic solutions (as is the case for AIUB's reduced dynamic POD results). The DEOS, DLR, and Eumetsat reduced dynamic orbits, in contrast, exhibit a higher dynamical stiffness and are therefore fairly insensitive to radial antenna offset errors. Aside from this bias, the height difference of individual reduced dynamics solutions exhibits a standard deviation of 1-2 cm, which underlines an excellent altimetric quality of the resulting orbit products.

A similar inconsistency between preflight calibrations and inflight measurements has been observed in the Jason mission. The application of an empirically derived GPS 
Table 3 Comparison of precise orbit determination position solutions from AIUB (BSW), DEOS (GEODYN), DLR (GHOST) and Eumetsat (NAPEOS) for GRAS/MetOp on days 360-262 of 2006

The upper right triangle gives the mean and standard deviation of the radial $(R)$, along-track $(T)$ and cross-track $(\mathrm{N})$ position differences. The lower left provides the corresponding $3 \mathrm{D}$ rms values

\begin{tabular}{|c|c|c|c|c|c|c|c|}
\hline \multirow{2}{*}{$\frac{\text { Position }(\mathrm{cm})}{\text { AIUB }}$} & \multirow[t]{2}{*}{ AIUB } & \multicolumn{2}{|c|}{ DEOS } & \multicolumn{2}{|c|}{ DLR } & \multicolumn{2}{|c|}{ EUM } \\
\hline & & $R$ & $-3.8 \pm 2.0$ & $R$ & $-3.3 \pm 1.4$ & $R$ & $-2.6 \pm 1.8$ \\
\hline & & $T$ & $-0.6 \pm 3.6$ & $T$ & $+0.5 \pm 1.9$ & $T$ & $+0.5 \pm 2.9$ \\
\hline & & $N$ & $-1.4 \pm 2.4$ & $N$ & $+0.9 \pm 1.3$ & $N$ & $-1.3 \pm 1.9$ \\
\hline \multirow[t]{3}{*}{ DEOS } & 6.3 & & & $R$ & $+0.5 \pm 1.6$ & $R$ & $+1.1 \pm 1.8$ \\
\hline & & & & $T$ & $+1.1 \pm 3.3$ & $T$ & $+1.1 \pm 3.5$ \\
\hline & & & & $N$ & $+2.3 \pm 2.5$ & $N$ & $+0.1 \pm 2.7$ \\
\hline \multirow[t]{3}{*}{ DLR } & 4.4 & & 5.1 & & & $R$ & $+0.6 \pm 1.4$ \\
\hline & & & & & & $T$ & $+0.0 \pm 2.7$ \\
\hline & & & & & & $N$ & -2.251 .2 \\
\hline EUM & 4.9 & & 5.0 & & 4.0 & & \\
\hline
\end{tabular}

Table 4 Comparison of precise orbit determination velocity solutions from AIUB (BSW), DEOS (GEODYN), DLR (GHOST) and Eumetsat (NAPEOS) for GRAS/MetOp on days 360-262 of 2006

The upper right triangle gives the mean and standard deviation of the radial $(R)$, along-track $(T)$ and cross-track $(N)$ velocity differences. The lower left provides the corresponding $3 \mathrm{D}$ rms values

\begin{tabular}{|c|c|c|c|c|c|c|c|}
\hline \multirow{2}{*}{$\begin{array}{l}\text { Velocity }(\mathrm{mm} / \mathrm{s}) \\
\text { AIUB }\end{array}$} & \multirow[t]{2}{*}{ AIUB } & \multicolumn{2}{|c|}{ DEOS } & \multicolumn{2}{|c|}{ DLR } & \multicolumn{2}{|c|}{ EUM } \\
\hline & & $R$ & $+0.01 \pm 0.03$ & $R$ & $-0.01 \pm 0.02$ & $R$ & $-0.01 \pm 0.03$ \\
\hline & & $T$ & $-0.04 \pm 0.02$ & $T$ & $-0.04 \pm 0.02$ & $T$ & $-0.03 \pm 0.04$ \\
\hline & & $N$ & $-0.00 \pm 0.03$ & $N$ & $-0.00 \pm 0.02$ & $N$ & $-0.00 \pm 0.03$ \\
\hline DEOS & 0.06 & & & $R$ & $-0.01 \pm 0.03$ & $R$ & $-0.01 \pm 0.03$ \\
\hline & & & & $T$ & $+0.01 \pm 0.02$ & $T$ & $+0.01 \pm 0.05$ \\
\hline & & & & $N$ & $+0.00 \pm 0.03$ & $\mathrm{~N}$ & $+0.00 \pm 0.03$ \\
\hline DLR & 0.05 & & 0.05 & & & $\mathrm{R}$ & $-0.00 \pm 0.03$ \\
\hline & & & & & & $\mathrm{T}$ & $+0.01 \pm 0.04$ \\
\hline & & & & & & $\mathrm{N}$ & $-0.00 \pm 0.02$ \\
\hline EUM & 0.07 & & 0.07 & & 0.06 & & \\
\hline
\end{tabular}

Table 5 Comparison of kinematic (KIN) and reduced dynamic (RD) solutions for GRAS/MetOp on days 360-262 of 2006

The tables give the mean and standard deviation of the radial $(R)$, along-track $(T)$ and crosstrack $(N)$ position differences as well as the 3D rms values

\begin{tabular}{|c|c|c|c|c|c|c|c|c|}
\hline \multirow{2}{*}{$\frac{\text { Position }(\mathrm{cm})}{\text { AIUB (KIN) }}$} & \multicolumn{2}{|c|}{ AIUB (RD) } & \multicolumn{2}{|c|}{ DEOS (RD) } & \multicolumn{2}{|c|}{ DLR (RD) } & \multicolumn{2}{|c|}{ EUM (RD) } \\
\hline & $R$ & $-0.1 \pm 5.0$ & $R$ & $-3.9 \pm 5.7$ & $\mathrm{R}$ & $-3.4 \pm 5.5$ & $R$ & $-2.8 \pm 5.4$ \\
\hline & $T$ & $+0.1 \pm 3.5$ & $T$ & $-0.5 \pm 5.2$ & $T$ & $+0.6 \pm 4.3$ & $T$ & $+0.6 \pm 4.7$ \\
\hline & $N$ & $-0.1 \pm 2.7$ & $N$ & $-1.4 \pm 3.8$ & $N$ & $+0.9 \pm 3.3$ & $N$ & $-1.4 \pm 3.6$ \\
\hline & $3 \mathrm{D}$ & 6.7 & $3 \mathrm{D}$ & 9.6 & $3 \mathrm{D}$ & 8.5 & $3 \mathrm{D}$ & 8.6 \\
\hline \multirow[t]{4}{*}{ DLR (KIN) } & $R$ & $+1.1 \pm 6.5$ & $R$ & $-2.7 \pm 6.9$ & $R$ & $-2.2 \pm 6.7$ & $R$ & $-1.5 \pm 6.6$ \\
\hline & $T$ & $-0.4 \pm 4.9$ & $T$ & $-0.9 \pm 6.0$ & $T$ & $+0.1 \pm 5.0$ & $T$ & $+0.2 \pm 5.4$ \\
\hline & $N$ & $+0.5 \pm 4.4$ & $N$ & $-0.9 \pm 4.9$ & $N$ & $+1.4 \pm 4.7$ & $N$ & $-0.9 \pm 4.9$ \\
\hline & $3 \mathrm{D}$ & 9.4 & $3 \mathrm{D}$ & 10.8 & $3 \mathrm{D}$ & 10.0 & $3 \mathrm{D}$ & 10.0 \\
\hline
\end{tabular}

antenna phase center map and offset of about $4 \mathrm{~cm}$ has become standard practice for precise orbit determination of this spacecraft (Luthke et al. 2003; Haines et al. 2003). An effort has therefore been made to construct a phase center correction map for MetOp-A from the average residuals of the ionosphere-free L1/L2 carrier phase measurements relative to the reduced dynamics orbit solution. Based on the available data set, phase center variations have been computed on a grid of about $1.5^{\circ}$ resolution. The resulting correction is illustrated in Fig. 10. It must be applied in addition to a priori L1/L2 phase center variation given by the ground calibration. It may be noted that the supplementary phase corrections derived from the inflightcalibration are substantial (typically 5-10 $\mathrm{mm}$ ) and exhibit a highly granular structure that is evidently caused by multipath effects.

Though preliminary in nature, the empirical phase center correction shows a clear benefit when applied in the 

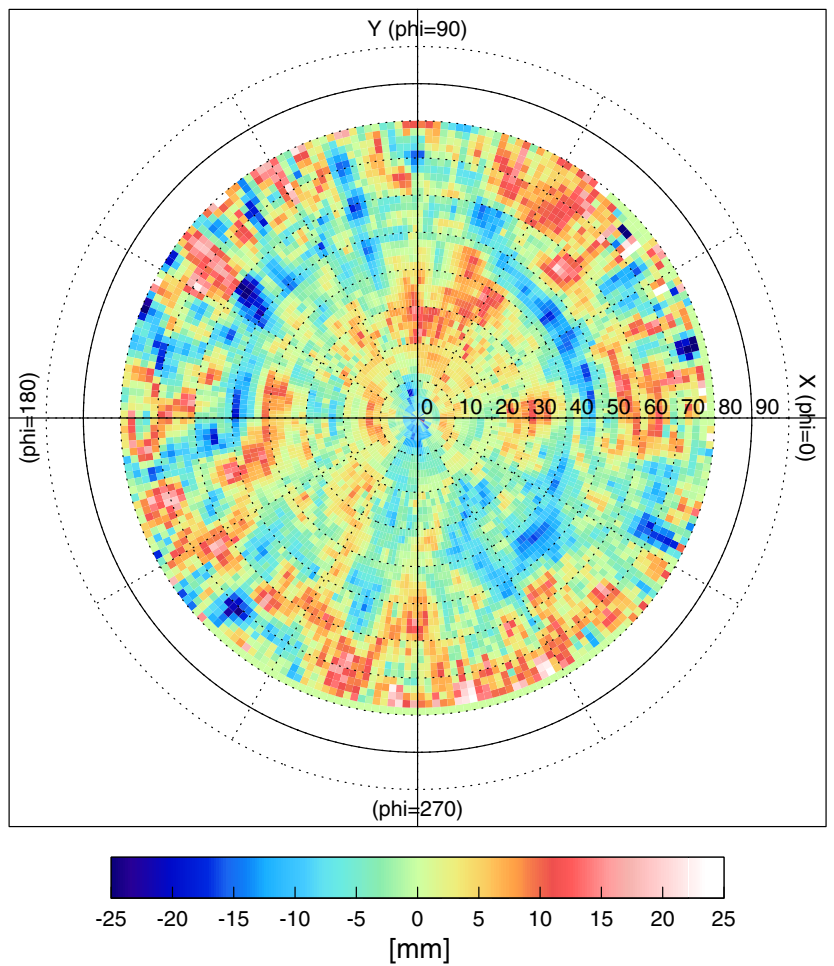

Fig. 10 Phase center correction for the ionosphere-free L1/L2 combination as derived from carrier phase residuals in the precise orbit determination. The employed antenna coordinate system is aligned with the spacecraft body axes

orbit determination process. In an undifferenced processing, the rms carrier phase residuals were found to decrease from 11 to $7 \mathrm{~mm}$ for a reduced dynamics POD and from 7 to $5 \mathrm{~mm}$ for a purely kinematic positioning. A consistent improvement was obtained for test days, both inside and outside the data arc that was used to establish the phase correction map. Following the correction, the rms carrier phase residuals are consistent with values obtained in the GRACE mission. They imply an upper limit of about $2 \mathrm{~mm}$ for the average noise of the single-frequency semi-codeless carrier phase measurements, but include also the contributions from GPS clock solution errors. Since no obvious variation of the rms carrier phase residuals with elevation is present, the latter errors appear to dominate the residuals budget for all but very low elevations. Concerning the orbit solutions themselves, only moderate changes $(<1 \mathrm{~cm} 3 \mathrm{D}$ rms) were observed in the reduced dynamics case. However, a substantial improvement (from about 10.5 to $7.5 \mathrm{~cm}$ $3 \mathrm{D} \mathrm{rms}$ ) in the consistency of GHOST kinematic and reduced dynamics solution was achieved, when applying the phase corrections.

The velocity solution (Table 4) obtained as part of the reduced dynamics orbit determination exhibit a representative standard deviation of $0.03 \mathrm{~mm} / \mathrm{s}$ in the along-track direction, which is well within the requirement of $0.1 \mathrm{~mm} / \mathrm{s}$ for occultation data analysis. A bias of about $0.04 \mathrm{~mm} / \mathrm{s}$ can be observed in the AIUB solution, which is a direct consequence of the aforementioned radial position offset. In case of the Eumetsat solution, a slightly higher noise is observed than for the other velocity solutions, since the corresponding values were derived from interpolation and differentiation of position information with limited numerical precision. At the $1 \mathrm{~mm}$ resolution of the SP3 ephemeris format (Remondi 1991) and a $30 \mathrm{~s}$ step size, this contributes a random error of about $0.03 \mathrm{~mm} / \mathrm{s}$, which is of similar magnitude as the actual orbit determination errors.

\section{Summary and conclusions}

The measurement quality of the GRAS GPS receiver and the achievable orbit determination performance have been assessed based on a MetOp-A test data collected with the zenith looking navigation antenna. Overall, the results underline the high quality of the instrument and demonstrate a competitive performance in comparison to the commonly used BlackJack/IGOR receiver. Both receivers exhibit a very similar sensitivity; the differences in the measurement noise can mainly be attributed to the choice of different loop settings. The impact of multipath due to diffuse reflection in the vicinity of the GRAS zenith antenna on MetOp is evident both in pseudorange and carrier phase measurements but does not affect the orbit determination in a critical manner. Precise orbit solutions generated by four different institutions based on the same data set show a representative consistency of $5 \mathrm{~cm}$ (3D $\mathrm{rms}$ ) and $0.06 \mathrm{~mm} / \mathrm{s}$ for position and velocity, respectively. This is compatible with other science missions and well within the specified limits for occultation data analysis.

Further work is presently planned in order to better understand and calibrate systematic phase center variations and multipath effects in the MetOp-A environment. Preliminary results indicate that an improved consistency of kinematic and reduced dynamic orbit determination results can be achieved by a $3 \mathrm{~cm}$ radial phase center offset and empirical phase center map. However, substantially longer data arcs would be required to consolidate the initial results.

Acknowledgments The authors would like to thank the staff of GMV for the preparation of sample GRAS data sets and preprocessing information during the early phase of this study. Information on the GRAS instrument design and preflight testing has been contributed by J. Christensen (SAAB Space AB) and F. Zangerl (Austrian Aerospace), which are gratefully acknowledged. Precise orbit and clock solutions have been obtained from the IGS and the CODE analysis center. 


\section{References}

Agueda A, Zandbergen R (2004) NAPEOS mathematical models and algorithms, NAPEOS-MM-01, iss. 3.0, 04/06/2004, ESA/ESOC, Darmstadt

Bock H, Jäggi A, Svehla D, Beutler G, Hugentobler U, Visser P (2007) Precise orbit determination for the GOCE satellite using GPS. Adv Space Res 39:1638-1647. doi:10.1016/j.asr.2007.02.053

Dach R, Hugentobler U, Fridez P, Meindl M (2007) Bernese GPS Software Version 5.0. University of Bern

Edwards PG, Berruti B, Blythe P, Callies J, Carlier S, Fransen C, Krutsch R, Lefebvre A-R, Loiselet M, Stricker N (2006) The MetOp satellite-weather information from polar orbit. ESA Bull 127:8-17

Haines B, Desai S, Willis P, Bertiger W (2003) Precise orbit determination for Jason-1: GPS and the 1-cm challenge. Geophys Res Abst 5:12378

Loiselet M, Stricker N, Menard Y, Luntama JP (2000) GRASMetOp's GPS-based atmospheric sounder. ESA Bull 102:38-44

Loiselet M, Stricker N, Christensen J, Carrascosa C (2007) In orbit verification results from GRAS receiver on MetOp-A Satellite. In: Proceedings of joint 2007 EUMETSAT meteorological satellite conference and the 15th American Meteorological Society (AMS) satellite meteorology and oceanography conference, Amsterdam, 24-28 September 2007

Luthke SB, Zelensky NP, Rowlands DD, Lemoine FG, Williams TA (2003) The 1-centimeter orbit: Jason-1 precision orbit determination using GPS, SLR, DORIS, and Altimeter data. Marine Geodesy, 26:399-421. doi:10.1080/01490410390256727

Marquardt C, Andres Y, von Engeln A, Clerigh EO, Sancho F (2007) GRAS on Metop: data quality. In: Proceedings of second FORMOSAT-3/COSMIC data users workshop, Boulder, Colorado, 22-24 October 2007

Montenbruck O, Kroes R (2003) In-flight performance analysis of the CHAMP BlackJack receiver. GPS Solut 7:74-86

Montenbruck O, van Helleputte T, Kroes R, Gill E (2005) Reduced dynamic orbit determination using GPS code and carrier measurements. Aerosp Sci Technol 9(3):261-271. doi:101016/ jast200501003

Montenbruck O, Garcia-Fernandez M, Williams J (2006) Performance comparison of semi-codeless GPS receivers for LEO satellites. GPS Solut 10:249-261. doi:101007/s10291-006-0025-9

Press WH, Flannery BP, Teukolsky SA, Vetterling WT (1992) Numerical recipes in $\mathrm{C}$ - the art of scientific computing, 2nd edn. Cambridge University Press, Cambridge

Reichinger H, Griesauer F, Zangerl F, Consoli A, Piazza F, GarciaRodriguez A (2006) A highly integrated modular European spaceborne dual frequency GPS-receiver, NAVITEC'2006, Noordwijk, 11-13 December 2006

Remondi BW (1991) NGS second generation ASCII and binary orbit formats and associated interpolation studies. In: Proceedings of the twentieth general assembly, International Union of Geodesy and Geophysics, Vienna, Austria, 11-24 August 1991

Rowlands D, Marshall JA, McCarthy J et al (1995) GEODYN system description II, vols 1-5. Hughes STX Corp, Greenbelt

Rummel R, Gruber T, Koop R (2004) High level processing facility for GOCE: products and processing strategy. In: Proceedings of the second international GOCE user workshop "GOCE, The Geoid and Oceanography”, ESA-ESRIN, Frascati, Italy, 8-10 March 2004, ESA SP-569
SAAB (2004) METOP-GRAS Measurement Data Interpretation and Description, P-GRM-SPC-0036-SE, Issue 7, 2 September 2004, Saab Ericsson Space

Silvestrin P, Cooper J (2000) Method of processing of signals of a satellite positioning system. US Patent 6157341, 5 Dec 2000

Silvestrin P, Bagge R, Bonnedal M, Carlström A, Christensen J, Hägg M, Lindgren T, Zangerl F (2000) Space-borne GNSS Radio Occultation Instrumentation for Operational Applications. In: Proceedings of the ION-GPS-2000, Salt Lake City, 19-22 September 2000, pp 872-880

Svehla D, Rothacher M (2005), Kinematic precise orbit determination for gravity field determination. In: Sanso F (ed), A window on the future of Geodesy, proceedings of the international association of Geodesy IAG general assembly Sapporo, Japan, 30 June-11 July 2003, pp 181-188. doi 10.1007/b139065

van Dierendonck AJ (1995) GPS receivers. In: Spilker J, Parkinson B (eds) Global positioning system: theory and applications, vol. I. American Institute of Aeronautics and Astronautics Inc., Washington

Ward P (1996) Satellite signal acquisition and tracking. In: Kaplan ED (ed) Understanding GPS principles and applications. Artech House Publishers, USA

Woo KT (2000) Optimum semi-codeless carrier phase tracking of L2. Navigation. J Inst Navig 47(2):82

Zin A, Landenna S, Conti A, Marradi L, Di Raimondo MS (2006) ENEIDE: an experiment of a Spaceborne, L1/L2 Integrated GPS/WAAS/EGNOS Receiver, European Navigation Conference 2006

\section{Author Biographies}

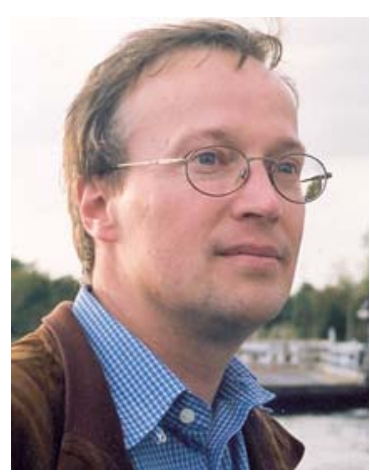

Dr. Oliver Montenbruck is the head of the GNSS Technology and Navigation Group at DLR's German Space Operations Center. His current research activities comprise spaceborne GPS applications, autonomous navigation systems and spacecraft formation flying.

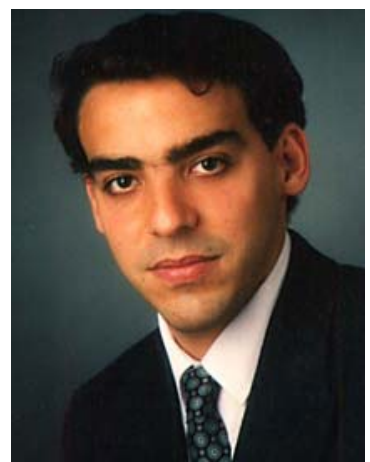

Yago Andres is a flight dynamics engineer at Eumetsat, Darmstadt, where he's in charge of MetOp-A precise orbit dynamics operations. determination and flight 

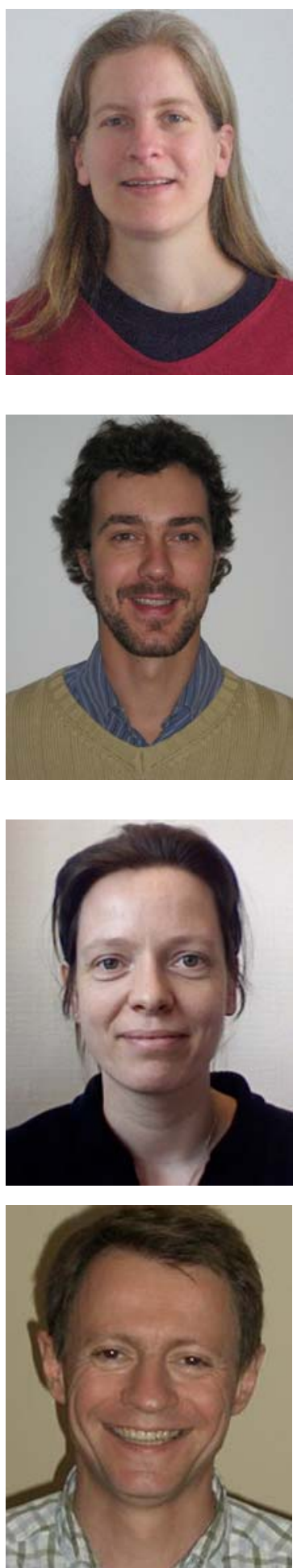

Dr. Heike Bock is a senior researcher at the Astronomical Institute of the University of Bern. She's presently in charge of precise orbit determination within the GOCE project as well as the routine processing of GNSS orbits and clocks for the CODE analysis center.

Tom van Helleputte is a $\mathrm{Ph} . \mathrm{D}$. candidate at the Delft Institute of Earth Observation and Space Systems (DEOS), where he contributes to the analysis of space-borne accelerometer data from LEO satellites and supports the GOCE quick-look orbit determination.

Jose van den IJssel is a senior researcher at the Delft Institute of Earth Observation and Space Systems (DEOS) with focus on precise orbit determination of LEO satellites.

Marc Loiselet is a senior engineer in the Directorate of Earth Observation Programmes at ESA/ESTEC where he is in charge of Performance and Processing of the GRAS/MetOp project.

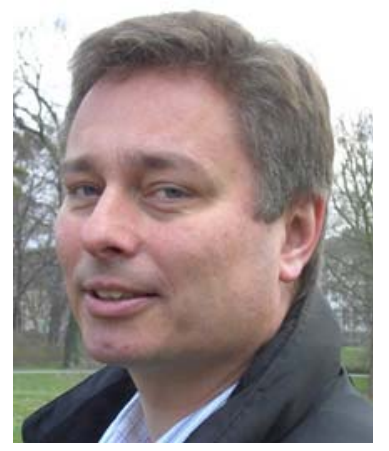

Christian Marquardt, Ph.D. is Polar System Product Expert and responsible for the GRAS science data processing at EUMETSAT Darmstadt.
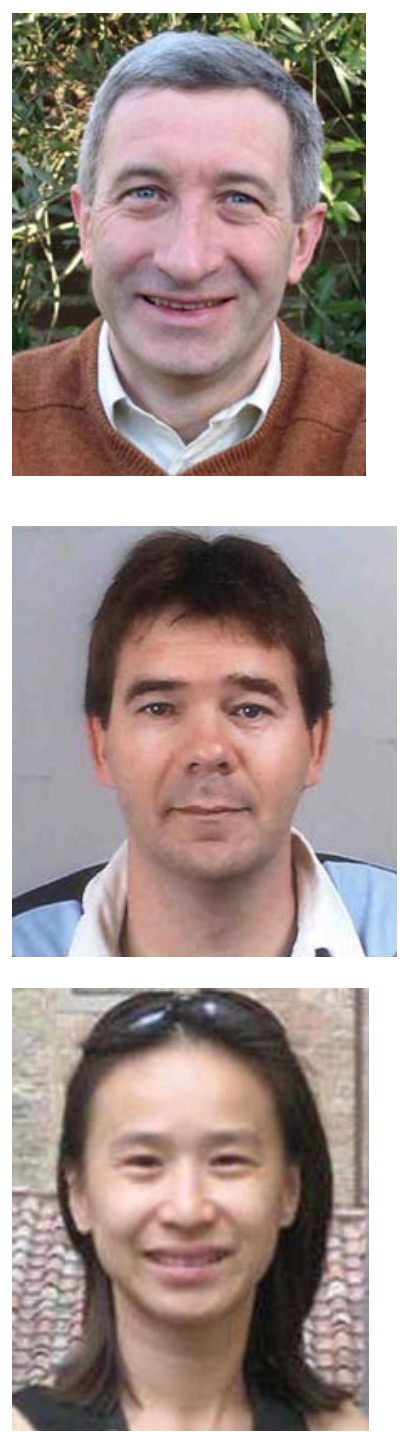

Pieter Visser, Ph.D. is an associate professor for astrodynamics at the Delft Institute of Earth Observation and Space Systems (DEOS). The focus of his research activities lies in the area of orbit and gravity field determination.

Pierluigi Silvestrin is the head of the Future Missions Division grammes directorate at ESA E. He was responsible for instrument and holds a patent for the semi-codeless tracking technique used with the AGGA2 correlator.

Yoke Yoon, Ph.D. is a senior flight dynamics analyst at DLR/ GSOC with responsibility for the TerraSAR-X precise orbit determination. 